\title{
Effects of Bone Cement Distribution on Adjacent Endplates After Percutaneous Vertebroplasty for Thoracolumbar Fractures: A Finite Element Analysis
}

Ye Han

Affiliated Hospital of Hebei University

Jincheng Wu

Tianjin Medical University

Xiaodong Wang

Affiliated Hospital of Hebei University

Wenshan Gao

Affiliated Hospital of Hebei University

Jianzhong Wang

Affiliated Hospital of Hebei University

Shaosong Sun

Affiliated hospital of Heibei University

Zepei Zhang

Tianjin Hospital

Kepeng Li

Tianjin Medical University

Miao Jun (D86094310@qq.com )

Tianjin Hospital https://orcid.org/0000-0002-5533-6535

\section{Research Article}

Keywords: Percutaneous vertebroplasty, PVP, Cement, Finite element analysis, Thoracolumbar compression fractures

Posted Date: March 10th, 2021

DOl: https://doi.org/10.21203/rs.3.rs-296770/v1

License: (c) (1) This work is licensed under a Creative Commons Attribution 4.0 International License.

Read Full License 


\section{Abstract}

BACKGROUND: Percutaneous vertebroplasty (PVP) is a common surgical method for the treatment of thoracolumbar compression fractures. Currently, no biomechanical analysis has been performed examining the effects of cement distribution and positioning on the overall thoracolumbar range of motion (ROM) and the stress applied to adjacent endplates.

METHODS: A model of PVP following vertebral compression fracture was established based on computed tomography data. Cement was injected into the T12 vertebral body. Depending on the location of the injection site, the model was divided into a median cement model, a left cement model, an upperleft cement model, and a lower-left cement model. The postoperative thoracolumbar ROM and biomechanical changes to the adjacent endplates were analyzed.

RESULTS: After cement injection, the overall ROM for the thoracolumbar region increased compared with that before cement injection. The maximum ROM of flexion was $9.28^{\circ}$ for the left model; the maximum ROM of extension was $10.90^{\circ}$ for the upper-left model; the maximum left and right rotations were $8.47^{\circ}$ and $8.52^{\circ}$, respectively, for the left model; the maximum left bending was $13.10^{\circ}$ for the left model; and the maximum right bending was $13.43^{\circ}$ for the left model. The stress applied to the adjacent vertebral endplate in the median cement model increased compared with the intact model, and the von Mises stress (VMS) value changed with different cement positions.

CONCLUSION: After cement injection, the overall stress value of the endplate adjacent to the vertebral body increased, and when the position of the cement shifts, the maximum VMS increased further for some positions, and the stress value for the endplate adjacent to the vertebral body increased, which may cause fractures in the relative position.

\section{Background}

Osteoporosis is a common disease among older individuals, and osteoporotic vertebral compression fractures (OVCF) are common complications associated with osteoporosis. OVCF commonly occurs in the thoracolumbar region, and the primary clinical manifestations of OVCF include pain and spinal deformity. Due to increased pain, the activity of OVCF patients is often reduced, and various complications, including bedsores, lower limb venous thrombosis, and drop pneumonia, may occur, significantly increasing the mortality rate of OVCF patients. With the overall aging of the population, the incidence of OVCF increases annually. Decreased estrogen levels and associated losses in bone mineral density after menopause likely contribute to the incidence of OVCF being significantly higher in women than in men.

Many methods exist to treat OVCF. Polikeit et al. (1) injected cement into the compressed vertebral body for the first time and reported a good analgesic effect, after which this technique was widely used.

Percutaneous vertebroplasty (PVP) is a new surgical method based on cement injection for the treatment of OVCF, with a short operation time, a good analgesic effect, and rapid clinical adoption (2). However, as 
technologies continue to develop, some disadvantages may also become apparent, such as the recurrence of fractures in the adjacent vertebral bodies after surgery $(3,4)$. The recurrence of adjacent vertebral fractures has been suggested to be associated with postoperative biomechanical changes, such as varying amounts of injected cement, which can directly affect the stress applied to the affected vertebral body and adjacent vertebral bodies (5). However, no relevant studies have reported on the effects of cement distribution on adjacent vertebral bodies. We attempted to analyze the biomechanical effects of bone cement on adjacent vertebral bodies by applying the finite element analysis method to reconstruct models featuring different distributions of bone cement within the vertebral body. Through this study, we hope to provide a relevant basis of information to guide clinical surgery.

\section{Methods}

\section{Design, location, and timing}

We performed a finite element analysis of patients who were treated between June 10, 2020, and November 10, 2020, at the Department of Spinal Surgery, Tianjin Hospital, Tianjin University.

\section{Participants}

Volunteers were recruited from the Department of Spinal Surgery, Tianjin Hospital, Tianjin University, and a single individual was selected. The participant was male, 42 years old, $178 \mathrm{~cm}$ in height, $72 \mathrm{~kg}$ in weight, and underwent spinal computed tomography (CT) scan and three-dimensional reconstruction. Magnetic resonance imaging was performed to exclude additional spinal diseases. After obtaining consent from the patient, a written informed consent form was signed in accordance with the relevant regulations and submitted to the Ethics Committee for approval.

\section{Acquisition and reconstruction of CT images}

We obtained 128-row, 256-slice General Electric Company spiral CT thin-section scans (Sensation16, Siemens, Germany) with a slice thickness of $1-\mathrm{mm}$ and a resolution of $512 \times 512$. Sagittal twodimensional tomography images of the T8-L3 vertebral bodies were obtained, and image files were saved in DICOM format.

DICOM images were imported into Mimics 20.0 (Materials Company, Leuven, Belgium) to create a 3dimensional (3D) vertebral surface model from the T10 to the $L 2$, which was used to generate STL format files. After wrapping, smoothing, and the removal of excess triangular shapes using 3-Matic12.0 software (Materialise Inc.), the images were imported into Geomagic Studio 12.0 (Geomagic, NC, USA) for solidification.

Hypermesh (Altair Engineering, Troy, MI, USA) was used to grid and construct the intervertebral disc, bone, and ligament structures. The intervertebral disc was composed of annulus fibrosus matrix, nucleus pulposus, annulus fibrosus fibers, and upper and lower endplates, and the nucleus pulposus accounted for $43 \%$ of the total intervertebral disc (6). The surgical model was processed in Hypermesh, and the 
cement model was made using Proe software (Parametric Technology Corporation, Massachusetts, USA) and assembled in Hypermesh. Abaqus (Hibbitt, Karlsson, and Sorensen, Inc., Providence, RI, USA) was used for material property definition, model assembly, loading, and finite element analysis. The material properties of this study (7-9) were validated based on published finite element models and data regarding the thoracolumbar spine of human cadavers.

\section{Simulation of kyphoplasty model}

A T12 vertebral body extract was established using Geomagic Studio and used to simulate the surgical process, changing the cancellous bone of the T12 vertebral body to match the material properties of the cement injected at various sites, based on a 4-ml cement volume, as described by a previous study. This method was used to establish five models: A. complete model; B. cement distribution in the middle of the T12 (middle model); C. cement distribution in the left of the T12 (Left Model), the middle coronal plane of the bone cement model is consistent with the middle coronal plane of T12; D. cement distribution on the upper-left side of the T12, in which the uppermost distance of the cement model is $0.2 \mathrm{~cm}$ from the T12 upper endplate (upper-left model); E. cement distribution on the lower-left side of the T12, in which the uppermost distance of the cement model is $0.2 \mathrm{~cm}$ from the T12 lower endplate (lower-left model); (Figure 1).

\section{Evaluation of loading conditions and spinal motion simulation}

Abaqus was applied to evaluate the boundaries and loading conditions and the simulation of spinal motion. The L2 vertebral body was assumed to be fixed, and its substructure was set to the existing boundaries, without displacement or rotation, in all directions. Spinal motion in the sagittal, coronal, and transverse planes was defined as flexion-extension, lateral bending, and rotation, respectively. According to the human body's force-bearing capacity and previously published literature, an axial load of $200 \mathrm{~N}$ and an additional torque load of $7.5 \mathrm{Nm}$ were applied to simulate the flexion, extension, lateral bending, and rotation of the spine. An axial load was applied to the superior surface of the T10 vertebral body, and a torsional load was applied to the center of the T10 vertebral body (10).

\section{Evaluation indicators}

Two measures were used to evaluate the mechanical performance of the construct: (1) ROM of the overall fixation (T10-L2) and (2) magnitude and distribution of von Mises stress (VMS) in the adjacent vertebral endplates (i.e., the inferior endplate at T11 and the superior endplate at L1). These metrics were chosen to assess the role of different surgical methods on the overall fixation system. Because only one subject was modeled, no statistical analysis was performed in this study.

\section{Results}

\section{Validation of the model}


The rationality of the model was verified by comparison with other biomechanical experiments based on finite element models. In this study, under the same loading conditions, the ROM values obtained for the complete model, at a moment of $7.5 \mathrm{~N}$, were consistent with previous related studies (11-13). Therefore, the finite element model used for this study appeared to be effective for use in the further simulation of thoracolumbar fractures.

\section{ROMs for the thoracolumbar segment}

After the injection of bone cement, the overall ROM value for the thoracolumbar region increased compared with that before the injection of cement. The maximum ROM of flexion was $9.28^{\circ}$ for the left model; the maximum ROM of hyperextension was $10.90^{\circ}$ for the upper-left model; the maximum left and right rotations were $8.47^{\circ}$ and $8.52^{\circ}$, respectively, for the left model; the maximum left bending was $13.10^{\circ}$ for the left model; and the maximum right bending was $13.43^{\circ}$ for the left model. See Figure 2 for the observed changes in specific ROM values.

\section{Stress profile of the lower endplate at T11}

After the injection of bone cement, the stress applied to the entire inferior endplate of the T11 increased compared with that before the injection of cement. The maximum VMS for flexion and hyperextension was observed in the lower-left model, resulting in $31.27 \mathrm{mPa}$ and $31.3 \mathrm{mPa}$, respectively. The maximum VMS for levorotation occurred in the left model, resulting in $12.22 \mathrm{mPa}$. The maximum VMS of dextrose occurred in the left model, resulting in $12.47 \mathrm{mPa}$. The maximum VMS of the left curve occurred in the upper-left model, at $31.06 \mathrm{mPa}$. The maximum VMS of the right curve occurred in the lower-left model, at $28.58 \mathrm{mPa}$. See Figure 3 for the strain diagram of the T11 inferior endplate.

\section{Stress profile of the superior endplate at L1}

After the injection of bone cement, the stress applied to the entire superior endplate of the L 1 increased compared with that before the injection of cement. The maximum VMS of flexion occurred in the left model, which was $29.11 \mathrm{mPa}$. The maximum VMS of extension occurred in the left model, which was $22.87 \mathrm{mPa}$. The maximum VMS of left rotation occurred in the left model, which was $10.04 \mathrm{mPa}$. The maximum VMS of right rotation occurred in the lower-left model, which was $11.64 \mathrm{mPa}$. The maximum VMS of left bending occurred in the lower-left model, which was $31.64 \mathrm{mPa}$. The maximum VMS of right bending occurred in the median model, which was $32.13 \mathrm{mPa}$. See Figure 4 for the stress diagram of the L1 superior endplate.

\section{Discussion}

The incidence of OVCFs has been increasing with an increasingly aging society, resulting in 1.4 million new cases reported worldwide each year (14). Another study examining 27 countries in the EU reported an OVCF incidence of $1.9 \%$ (15), and OVCF is more prevalent among women, occurring approximately 2-3.5 times more frequently in women than in men. OVCF occurred almost 8 times more frequently in women 
aged 85-89 years than in women aged 60-64 years. OVCF can be associated with other complications, including back pain, kyphotic deformity, and drop pneumonia, which can negatively affect the quality of life of patients and increase the risk of death $(16,17)$.

At present, the treatment options for OVCF primarily consist of conservative treatment and surgical treatment. Conservative treatment typically includes bed rest, the application of analgesic drugs, and wearing braces. If conservative treatment does not relieve pain, surgical treatment may be considered. Vertebroplasty and kyphoplasty are minimally invasive surgical modalities for the treatment of osteoporotic compression fractures $(18,19)$. The use of a device to provide distraction to the compressed vertebral body can restore the vertebral body height, and the intraoperative injection of bone cement can stabilize the fractured vertebral body. Numerous studies have shown that PVP is more effective for relieving pain than conservative treatment (20). However, with the increasing clinical application of PVP surgeries, some complications associated with the procedure have also begun to be gradually appreciated.

One of the primary complications associated with kyphoplasty is the development of new vertebral fractures, and the incidence of adjacent vertebral fractures accounts for $58.8 \%-67 \%$ of new vertebral fractures $(4,21)$. Current studies have identified numerous causes for adjacent vertebral fractures, including differences in cement volume, leakage, and vertebral vacuum fissures. David's study concluded that no significant increase in compressive stiffness or intradiscal pressure occurs when the amount of cement-filler exceeds $15 \%$, equal to approximately 4-6 $\mathrm{ml}$ (3). Jin suggested that the effective cut-off value for avoiding adjacent fractures was approximately $5.05 \mathrm{ml}$. A cement injection fraction of more than $20 \%$ will produce an increasing number of subsequent fractures, and an injection volume greater than 9.2 $\mathrm{ml}$ will certainly result in subsequent and adjacent fractures (22). According to previous studies and our own surgical experience, we used approximately $4 \mathrm{ml}$ of bone cement to fill the fracture, which was better able to restore the strength of the vertebral body $(23,24)$; moreover, based on surgical steps used to simulate balloon distraction, we applied an ellipsoid shape to the bone cement and performed the relevant measurements.

Biomechanical studies have shown that upper vertebral advancement is an important cause of adjacent vertebral fractures. Lee et al. performed a study of 402 patients and concluded that the offset generated by bone cement along the superior and inferior axis was a risk factor for the development of compression fractures in the adjacent vertebral bodies (25). Our study found that after the central injection of bone cement, the lower endplate stress of the upper vertebral body increased by $10.08 \%, 13.83 \%$, and $8.56 \%$ during flexion, hyperextension, and rotation, respectively, whereas stress decreased by $9.8 \%$ during flexion. The changes in stress in response to different movements changed further when the bone cement was offset, causing an increase in the VMS for certain movements, such as the maximum stress applied during the hyperextension of the lower-left model, which was $31.3 \mathrm{mPa}$. Following the central injection of bone cement, the upper endplate stress of the lower vertebral body also changed, increasing by $11.19 \%$, $14.58 \%, 3.58 \%$, and $1.12 \%$ during flexion, hyperextension, rotation, and lateral bending, respectively. Similarly, when the bone cement position was offset, some VMS stresses increased further, with a 
maximum stress level of $31.64 \mathrm{mPa}$ estimated during lateral bending movements for the lower-left model. This increase in the stress value occurred in the endplate adjacent to the repaired vertebral body, which may explain fractures that occur in adjacent structures.

Some studies have analyzed the uneven distribution of bone cement, which can cause strut-like effects. When bone cement is injected into the affected vertebra, the inward bulging of the endplate of the reinforced vertebral body decreases, resulting in the increased stiffness of the intervertebral disc and an increase in the inward bulging of the endplate of the adjacent vertebral body, which can result in the development of adjacent vertebral fractures $(26,27)$. Ottardi's study found that the superior endplate stress of the vertebral body increased by $15 \%-40 \%$ after the injection of bone cement, which may indirectly verify the "strut-like effect"(28). Dabirrahmani et al. suggested that the inferior endplate of the L2 and the superior endplate of the L4 vertebrae were the most prone to secondary fractures using a model of cement injection into the L3 vertebral body (29). Our study identified a similar situation, in which the maximum VMS of the endplate was often concentrated in the corresponding position of the cement, whereas the VMS associated with other positions was relatively low, which could cause the upper and lower endplates of the adjacent vertebral bodies to fracture first at the position corresponding with cement placement, resulting in the adjacent vertebral fracture.

Previous trials have typically examined a single vertebral body or an adjacent vertebral body as the object of biomechanical analysis and, therefore, could not analyze stress changes throughout the entire thoracolumbar region. We performed a finite element analysis of the entire thoracolumbar segment, which more fully reflected the stress changes associated with the entire thoracolumbar segment after cement injection. In addition, we simulated the distribution of various cement positions and found that when the cement was offset along the coronal or sagittal positions, the stress values applied to the endplates of adjacent vertebral bodies also changed, and for some movements, the endplate stress was significantly higher than that for the model when cement was injected in the middle of the vertebral body. This finding suggests that during clinical surgery, to improve the biomechanical function of the column, bone cement injections should be distributed along the middle of the vertebra to the greatest extent possible, which can reduce the change in stress applied to the upper and lower vertebral endplates. When the bone cement distribution is offset, either coronally or sagittally, the stress applied to the adjacent vertebral endplates can further increase, resulting in the fracture of adjacent vertebral segments.

This study has some limitations. First, the finite element model and the material properties of the bone cement applied to this model represent simplifications of the real situation, as is the stress loading. Second, this model only used a single individual, and individual differences, such as variations in vertebral bodies, ligaments, and other structural variations, may make these findings less generalizable. Third, the test did not construct a wedge model and only simulated the ideal result of complete recovery of vertebral body height following PVP. In practice, however, the vertebral body height is only partially restored in most patients. In future research, we hope these factors can be addressed to provide a more realistic model. 


\section{Conclusion}

After the injection of bone cement, the ROM value of the whole thoracolumbar segment increases, increasing the stress applied to the adjacent endplate. When the position of the bone cement is shifted sagittally or coronally, the stress of the corresponding endplate will further change, which increases the maximum stress, and can promote the occurrence of adjacent vertebral fractures. Biomechanically, the cement injection should be centered to the greatest extent possible to limit increases in the maximum stress values.

\section{Abbreviations}

PVP: percutaneous vertebroplasty, ROM: range of motion, VMS: von Mises stress, OVCF: osteoporotic vertebral compression fracture

\section{Declarations}

\section{Ethics approval and consent to participate}

The study was approved by the ethical committee of the participating hospitals. The subject signed informed consent. All clinical investigations were conducted according to the principles expressed in the Declaration of Helsinki.

\section{Availability of data and materials}

Please contact the corresponding author for data requests.

\section{Competing interests}

The authors declare that they have no competing interests.

\section{Funding}

Not applicable

\section{Authors' contributions}

JM contributed to data collection. YH studied the design. XW wrote the manuscript. JW analyzed the data. All authors read and approved the final manuscript.

\section{Acknowledgments}

Not applicable

\section{Consent for publication}


Written informed consent for publication was obtained from all participants

\section{References}

1. Polikeit A, Nolte LP, Ferguson SJ. The effect of cement augmentation on the load transfer in an osteoporotic functional spinal unit: finite-element analysis. Spine (Phila Pa 1976). 2003;28(10):9916.

2. Chen B, Li Y, Xie D, Yang X, Zheng Z. Comparison of unipedicular and bipedicular kyphoplasty on the stiffness and biomechanical balance of compression fractured vertebrae. Eur Spine J. 2011;20(8):1272-80.

3. Martincic D, Brojan M, Kosel F, Stern D, Vrtovec T, Antolic V, et al. Minimum cement volume for vertebroplasty. Int Orthop. 2015;39(4):727-33.

4. Tseng YY, Yang TC, Tu PH, Lo YL, Yang ST. Repeated and multiple new vertebral compression fractures after percutaneous transpedicular vertebroplasty. Spine (Phila Pa 1976). 2009;34(18):191722.

5. Rotter R, Schmitt L, Gierer P, Schmitz KP, Noriega D, Mittlmeier T, et al. Minimum cement volume required in vertebral body augmentation-A biomechanical study comparing the permanent SpineJack device and balloon kyphoplasty in traumatic fracture. Clin Biomech (Bristol, Avon). 2015;30(7):720-5.

6. Polikeit A, Ferguson SJ, Nolte LP, Orr TE. Factors influencing stresses in the lumbar spine after the insertion of intervertebral cages: finite element analysis. Eur Spine J. 2003;12(4):413-20.

7. Zhong ZC, Wei SH, Wang JP, Feng CK, Chen CS, Yu CH. Finite element analysis of the lumbar spine with a new cage using a topology optimization method. Med Eng Phys. 2006;28(1):90-8.

8. Baroud G, Nemes J, Ferguson SJ, Steffen T. Material changes in osteoporotic human cancellous bone following infiltration with acrylic bone cement for a vertebral cement augmentation. Comput Methods Biomech Biomed Engin. 2003;6(2):133-9.

9. Zhang L, Yang G, Wu L, Yu B. The biomechanical effects of osteoporosis vertebral augmentation with cancellous bone granules or bone cement on treated and adjacent non-treated vertebral bodies: a finite element evaluation. Clin Biomech (Bristol, Avon). 2010;25(2):166-72.

10. Han Y, Wang X, Wu J, Xu H, Zhang Z, Li K, et al. Biomechanical finite element analysis of vertebral column resection and posterior unilateral vertebral resection and reconstruction osteotomy. $\mathrm{J}$ Orthop Surg Res. 2021;16(1):88.

11. Alizadeh M, Kadir MR, Fadhli MM, Fallahiarezoodar A, Azmi B, Murali MR, et al. The use of X-shaped cross-link in posterior spinal constructs improves stability in thoracolumbar burst fracture: a finite element analysis. J Orthop Res. 2013;31(9):1447-54.

12. Panjabi MM, Oxland TR, Lin RM, McGowen TW. Thoracolumbar burst fracture. A biomechanical investigation of its multidirectional flexibility. Spine (Phila Pa 1976). 1994;19(5):578-85. 
13. Elmasry S, Asfour S, Travascio F. Effectiveness of pedicle screw inclusion at the fracture level in short-segment fixation constructs for the treatment of thoracolumbar burst fractures: a computational biomechanics analysis. Comput Methods Biomech Biomed Engin. 2017;20(13):141220.

14. Johnell 0 , Kanis JA. An estimate of the worldwide prevalence and disability associated with osteoporotic fractures. Osteoporos Int. 2006;17(12):1726-33.

15. Hernlund E, Svedbom A, Ivergard M, Compston J, Cooper C, Stenmark J, et al. Osteoporosis in the European Union: medical management, epidemiology and economic burden. A report prepared in collaboration with the International Osteoporosis Foundation (IOF) and the European Federation of Pharmaceutical Industry Associations (EFPIA). Arch Osteoporos. 2013;8:136.

16. Bliuc D, Nguyen ND, Milch VE, Nguyen TV, Eisman JA, Center JR. Mortality risk associated with lowtrauma osteoporotic fracture and subsequent fracture in men and women. JAMA. 2009;301(5):51321.

17. Clynes MA, Harvey NC, Curtis EM, Fuggle NR, Dennison EM, Cooper C. The epidemiology of osteoporosis. Br Med Bull. 2020;133(1):105-17.

18. Hulme PA, Krebs J, Ferguson SJ, Berlemann U. Vertebroplasty and kyphoplasty: a systematic review of 69 clinical studies. Spine (Phila Pa 1976). 2006;31(17):1983-2001.

19. Taylor RS, Taylor RJ, Fritzell P. Balloon kyphoplasty and vertebroplasty for vertebral compression fractures: a comparative systematic review of efficacy and safety. Spine (Phila Pa 1976). 2006;31(23):2747-55.

20. Yang W, Song J, Liang M, Cui H, Chen H, Yang J. Functional Outcomes and New Vertebral Fractures in Percutaneous Vertebroplasty and Conservative Treatment of Acute Symptomatic Osteoporotic Vertebral Compression Fractures. World Neurosurg. 2019;131:e346-e52.

21. Uppin AA, Hirsch JA, Centenera LV, Pfiefer BA, Pazianos AG, Choi IS. Occurrence of new vertebral body fracture after percutaneous vertebroplasty in patients with osteoporosis. Radiology. 2003;226(1):119-24.

22. Jin YJ, Yoon SH, Park KW, Chung SK, Kim KJ, Yeom JS, et al. The volumetric analysis of cement in vertebroplasty: relationship with clinical outcome and complications. Spine (Phila Pa 1976). 2011;36(12):E761-72.

23. Robinson Y, Heyde CE, Forsth P, Olerud C. Kyphoplasty in osteoporotic vertebral compression fractures-guidelines and technical considerations. J Orthop Surg Res. 2011;6:43.

24. Molloy S, Riley LH, 3rd, Belkoff SM. Effect of cement volume and placement on mechanical-property restoration resulting from vertebroplasty. AJNR Am J Neuroradiol. 2005;26(2):401-4.

25. Lee HJ, Park J, Lee IW, Yi JS, Kim T. Clinical, Radiographic, and Morphometric Risk Factors for Adjacent and Remote Vertebral Compression Fractures Over a Minimum Follow-up of 4 Years After Percutaneous Vertebroplasty for Osteoporotic Vertebral Compression Fractures: Novel Threedimensional Voxel-Based Morphometric Analysis. World Neurosurg. 2019;125:e146-e57. 
26. Baroud G, Nemes J, Heini P, Steffen T. Load shift of the intervertebral disc after a vertebroplasty: a finite-element study. Eur Spine J. 2003;12(4):421-6.

27. Baroud G, Heini P, Nemes J, Bohner M, Ferguson S, Steffen T. Biomechanical explanation of adjacent fractures following vertebroplasty. Radiology. 2003;229(2):606-7; author reply 7-8.

28. Ottardi C, La Barbera L, Pietrogrande L, Villa T. Vertebroplasty and kyphoplasty for the treatment of thoracic fractures in osteoporotic patients: a finite element comparative analysis. J Appl Biomater Funct Mater. 2016;14(2):e197-204.

29. 29.Dabirrahmani D, Becker S, Hogg M, Appleyard R, Baroud G, Gillies M. Mechanical variables affecting balloon kyphoplasty outcome--a finite element study. Comput Methods Biomech Biomed Engin. 2012;15(3):211-20.

\section{Figures}

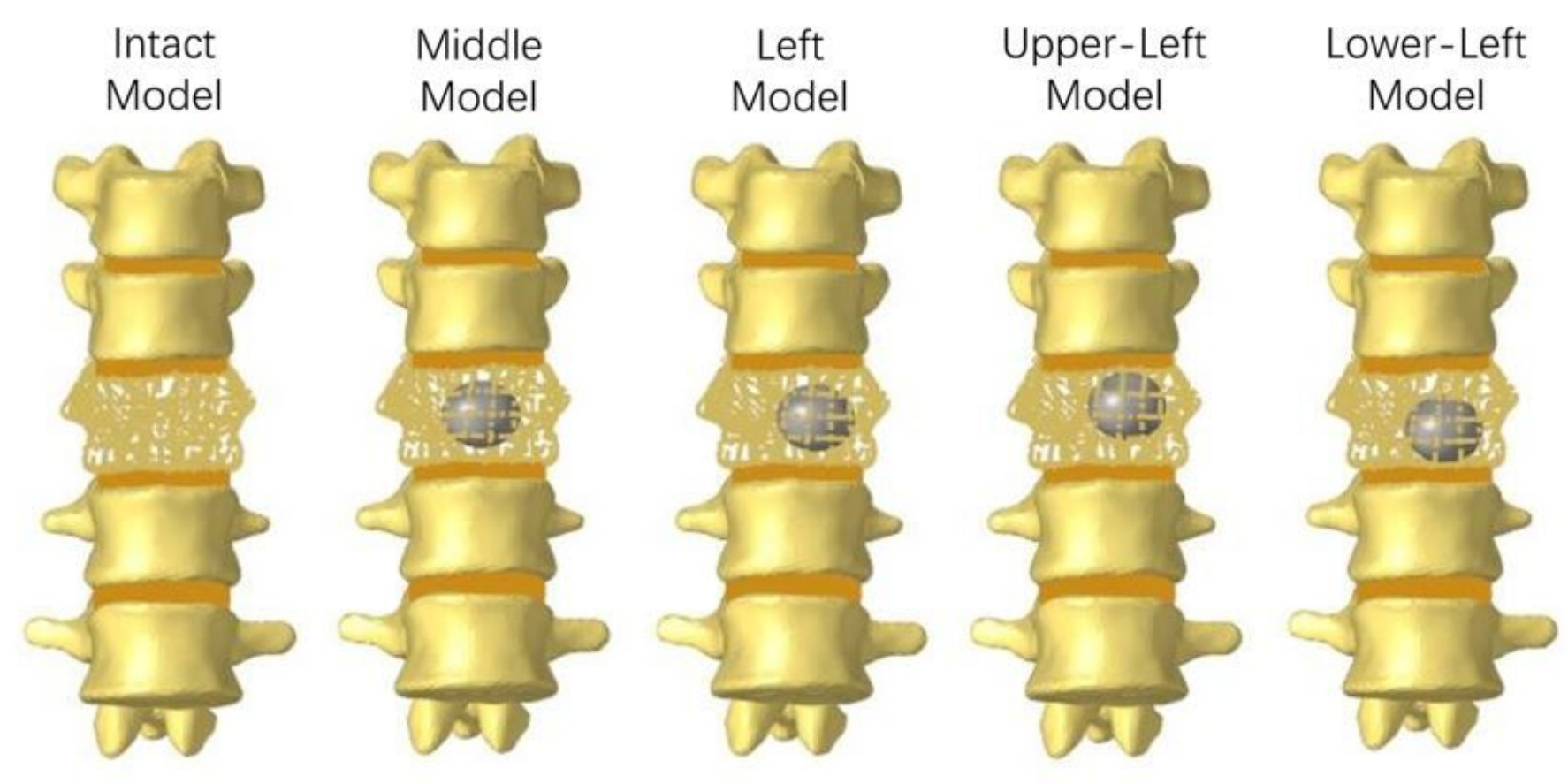

\section{Figure 1}

Finite element models of the fixation constructs 


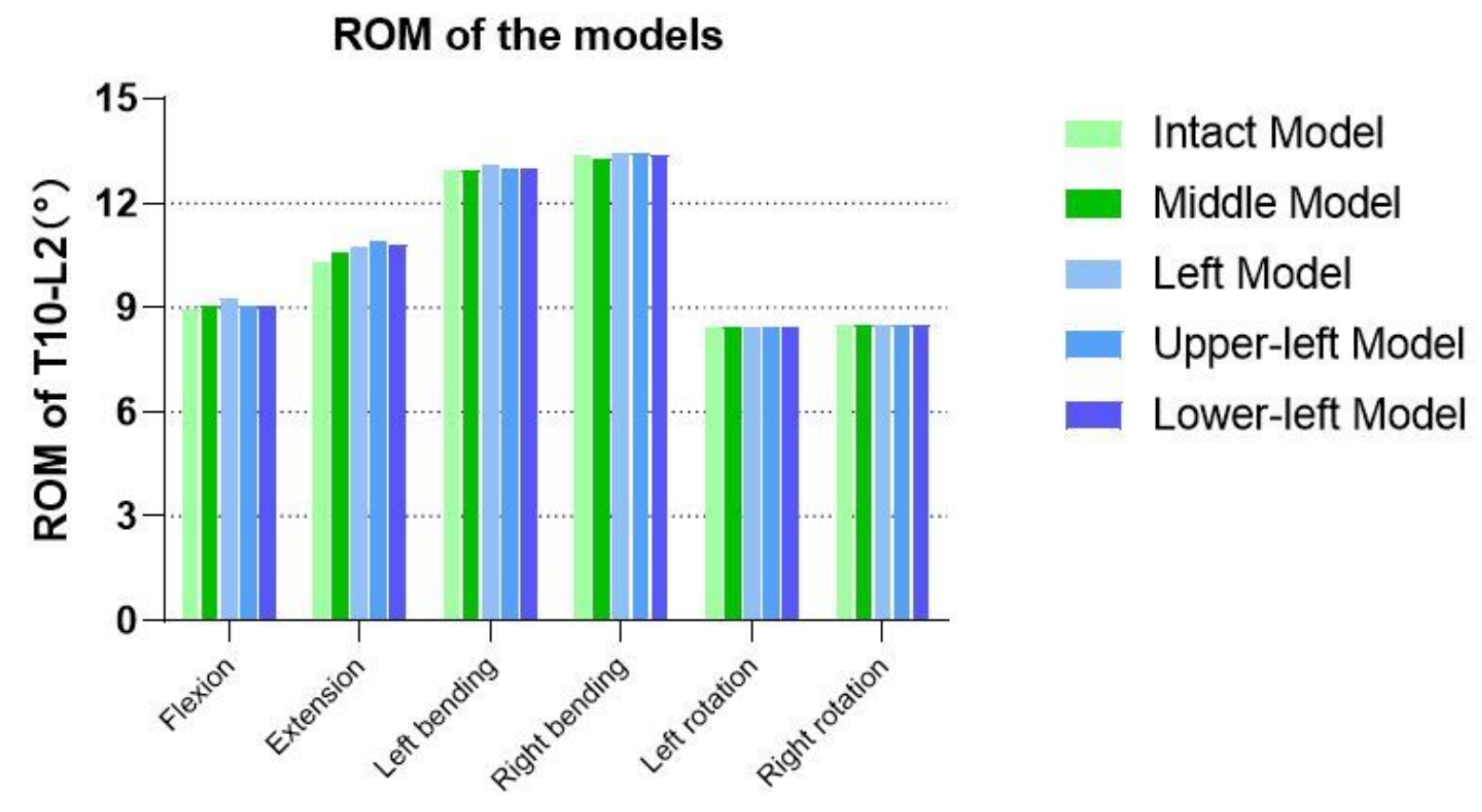

Figure 2

Figure for the observed changes in specific ROM values. 


$\begin{array}{ccccc}\text { Intact } & \text { Middle } & \text { Left } & \text { Upper-Left } & \text { Lower-Left } \\ \text { Model } & \text { Model } & \text { Model } & \text { Model } & \text { Model }\end{array}$
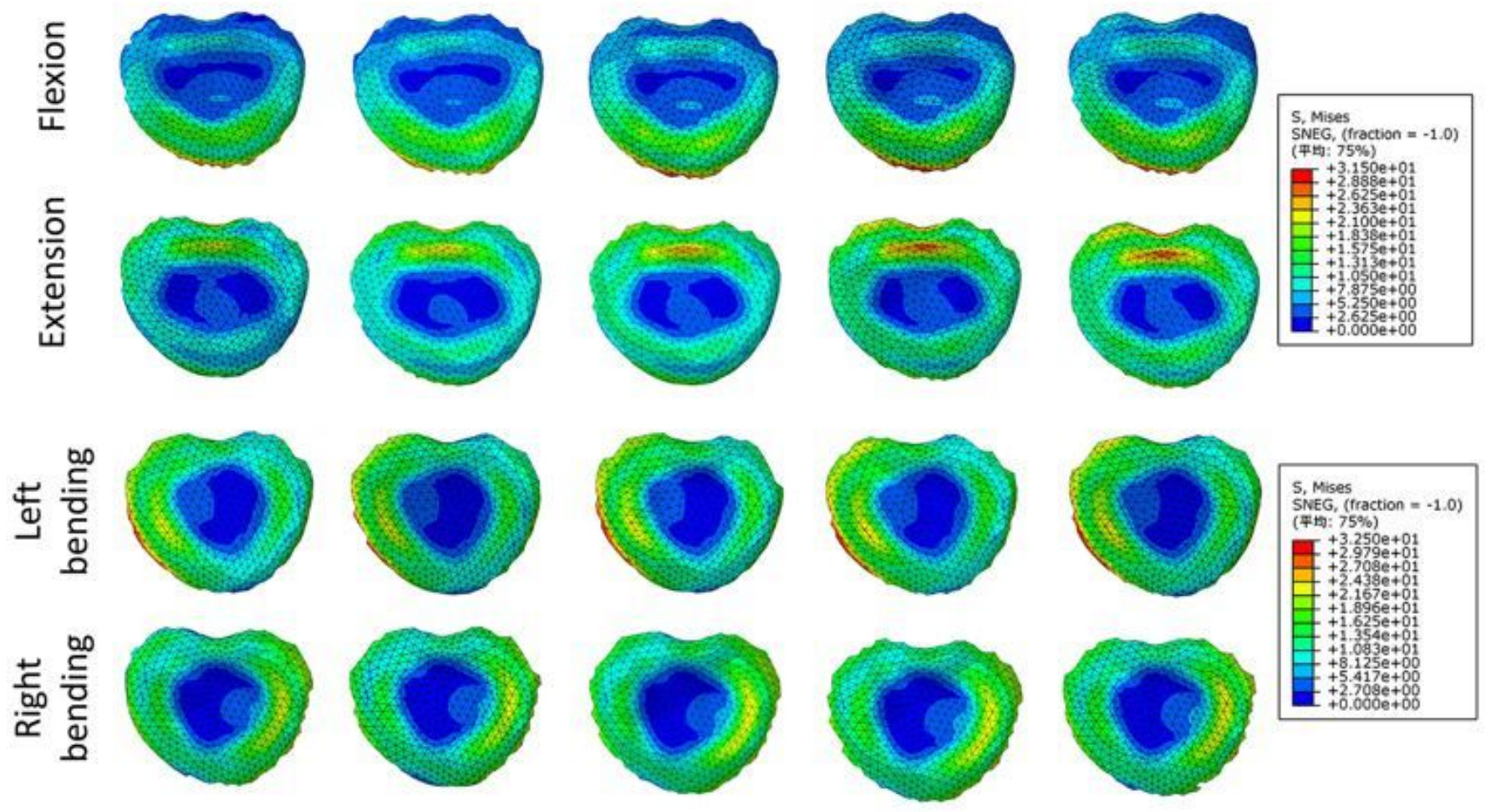

$+0.000 \mathrm{e}+00$
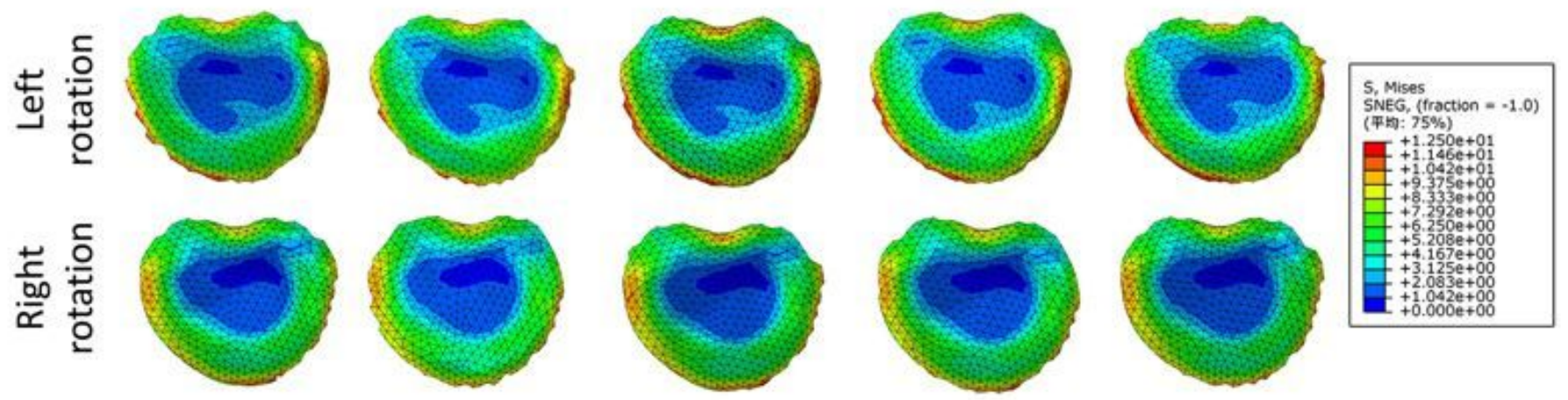

Figure 3

The stress in the inferior endplate of T11 


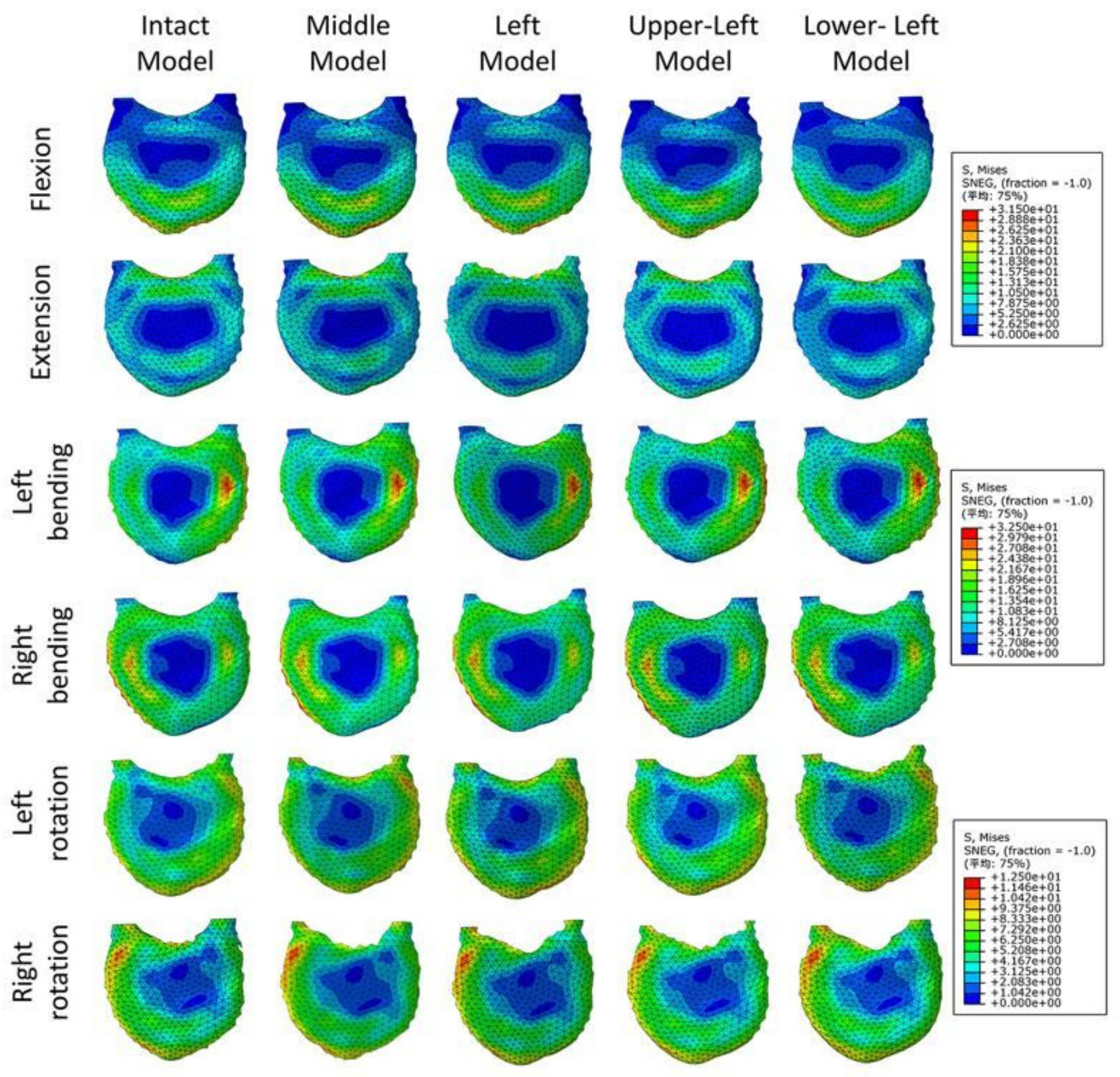

Figure 4

The stress in the upper endplate of $L 1$ 